Artículo científico - Humanidades

\title{
La transformación del paisaje agrario y la plasticultura en la ciénaga de Chapala, México
}

\section{The transformation of the agrarian landscape and plasticulture in the Ciénaga de Chapala, Mexico}

\author{
Conrado González Vera ${ }^{a}-J u a n$ Manuel Catalán Romerob_Francisco Sabino Covarrubias Machucac \\ a Instituto Politécnico Nacional, México. Contacto: cgonzalezv@ipn.mx \\ http://orcid.org/0000-0002-2695-3083 \\ b Instituto Politécnico Nacional, México. Contacto: jmcatalan@ipn.mx \\ c Universidad de La Ciénega del Estado de Michoacán de Ocampo, México. \\ Contacto: sabino27100@gmail.com
}

Recibido: 05 de noviembre de 2019

Aceptado: 19 de mayo de 2020

RESUMEN: El propósito de este trabajo es mostrar las transformaciones del paisaje agrario de la ciénaga de Chapala, México, durante el periodo comprendido entre la formación de los ejidos, la Revolución Verde y la agroindustria. El método seguido fue: i) identificación, análisis y fichado de libros y artículos que tratan el tema; ii) análisis del Padrón de Usuarios de los Módulos de Riego de La Palma, Cumuato y Ballesteros y del reporte de cultivos por zafra Distrito de Riego 024; iii) medición de la superficie de la ciénaga ocupada por acolchados, túneles e invernaderos y; iv) redacción de los resultados de la investigación. Se concluyó que los ejidatarios han ido perdiendo sus parcelas y se han convertido en proletarios, la agroindustria está incidiendo fuertemente en la agricultura cuyas tecnologías están transformando el paisaje, las relaciones sociales de producción y la cultura de los pueblos.

Palabras clave: ejido, paisaje agrario, plasticultura, revolución verde

ABSTRACT: The purpose of this work is to show the transformations of the agrarian landscape of the Ciénaga de Chapala, Mexico, from the formation of ejidos, the Green Revolution, and agro-industry. The method followed was: i) identification, analysis and file of books and articles dealing with the subject; ii) analysis of the census of users of the irrigation modules of La Palma, Cumuato and Ballesteros, and the report of crops by harvest from the Irrigation 
District 024- CONAGUA; iii) measurement of the surface of the swamp occupied by mulches, tunnels and greenhouses and; iv) writing the research results. It was concluded that the swamp peasantry has been proletarianized and that agroindustry is highly falling upon agriculture, whose technologies are transforming the landscape, the social relations of production, and the culture of the communities.

Keywords: agrarian landscape, plasticulture, green revolution.

\section{Introducción}

$\mathrm{P}$ aisaje agrario es el territorio destinado predominantemente a actividades agrícolas y ganaderas y la plasticultura, el uso de insumos plásticos con el fin de incrementar la producción agropecuaria y su calidad (Castillo, 2010, s/n), de ahí que el objetivo de este trabajo sea el de presentar una panorámica del proceso de transformación del paisaje agrario en la ciénaga de Chapala, haciendo hincapié en la incorporación del uso de plásticos en la agricultura. La introducción del cultivo de nuevas especies está asociada a las exigencias del mercado mundial, la inversión externa y la introducción de nuevas tecnologías que, en ocasiones, son aplicadas al cultivo de otras especies incluidas las tradicionalmente producidas. El cultivo de nuevas especies modifica el paisaje agrario.

La investigación se inició con la identificación, análisis y fichado de libros y artículos que tratan el tema; después se obtuvo y analizó el Padrón de Usuarios de los Módulos de Riego de La Palma, Cumuato y Ballesteros y el reporte de cultivos por zafra Distrito de Riego 024 elaborado por la Comisión Nacional del Agua; en seguida se midió la superficie de la ciénaga ocupada por acolchados, túneles e invernaderos comprendida en los 1,532 metros sobre el nivel del mar y; finalmente se redactaron los resultados de la investigación.

Los resultados obtenidos fueron los siguientes: i) En su mayoría, los ejidatarios han ido perdiendo sus parcelas y se han convertido en proletarios. ii) La llamada Revolución Verde introdujo el uso masivo de maquinaria e implementos agrícolas, fertilizantes y agroquímicos. iii) El uso de plásticos se inició en la ciénaga de Chapala en los cultivos de fresa, luego se utilizó en el cultivo de jitomate, sandía y melón y hoy día algunos agricultores lo usan en el cultivo de garbanza y maíz. 
La agricultura actualmente requiere de un enorme acopio de capital invertido, de relaciones comerciales internacionales y un nutrido ejército laboral de reserva. La utilización extensiva de plásticos en la producción agrícola ha generado acumulación de basura por los caminos, las parcelas y los canales de la ciénaga de Chapala.

\section{El Ejido y la Revolución Verde}

Los españoles consideraban que los humedales eran fuente de enfermedades y que los cuerpos de agua debían ser desecados para dedicarlos a la agricultura y la ganadería. Esta concepción fue heredada a gobernantes y empresarios mexicanos y a finales del siglo XIX, dinamitaron el entronque del río Santiago con el lago de Chapala (Tortolero, 2002, s/n), con el fin de reducir el nivel de sus aguas y ampliar la superficie cultivable. Los hacendados de Guaracha y Buenavista, poseedores de una conciencia mercantil, aprovecharon la creciente demanda internacional de alimentos _ granos en particular- (Boehm, 2005, 101), con la consecuente necesidad de explotar más tierras agrícolas. A principios del siglo XX durante el gobierno de Porfirio Díaz, se ordenó la construcción del dique de Maltaraña que mutiló más de 50 mil hectáreas al lago y dio pie a su venta (Burton, 1997, s/n).

Pero, el movimiento revolucionario de 1910 cambió el régimen de propiedad del suelo e inició el reparto agrario predominantemente bajo la forma de ejido. El objetivo de la formación de ejidos en México fue "restituir a los campesinos de la tierra que se supone era de su propiedad, expropiando las grandes extensiones de las haciendas porfirianas" (Trujillo, 2015, 135).

Las parcelas ejidales son cultivadas bajo el modelo campesino de producción para el autoconsumo, utilizando herramientas como troncos, yuntas, coas, azadones y casangas y técnicas como el barbecho, surcado, siembra a tapa-pie, entre otras. Con las herramientas y técnicas utilizadas, la superficie cultivada por un adulto y dos o tres infantes no rebasa las cuatro hectáreas y la producción de maíz las tres y media toneladas por hectárea. Los ejidatarios practicaban los policultivos y combinaban la siembra de maíz con la de calabaza o frijol, para aprovechar la única siembra al año que realizaban, por tratarse predominantemente de tierras de temporal. De este modo, obtenían el maíz y el frijol que constituían la dieta básica de sus familias. 
El ejidatario enfrentaba el problema de la adquisición de semillas para siembra y el de cubrir los gastos de subsistencia de la familia durante todo el año, sin tener ingresos antes de la cosecha. Para atender estos problemas, el gobierno de Lázaro Cárdenas dotó de una yunta de bueyes o de un tronco de mulas con avío a cada ejidatario, creó el Banco Nacional de Crédito Ejidal y la Aseguradora Nacional Agrícola y Ganadera, pero el banco financiaba sólo el costo de los insumos y las labores agrícolas y la aseguradora ese monto, pero no la subsistencia de los ejidatarios en periodos de estiaje, lo cual los obligaba a solicitar créditos a los prestamistas.

Muchas parcelas ejidales fueron abandonadas, rentadas o vendidas y muchas de ellas quedaron en manos de los prestamistas y registradas a nombre de sus familiares o amigos, pero las técnicas y las herramientas de trabajo agrícola empezaron a sufrir transformaciones hasta los años cincuenta con la introducción de tractores (Tortolero, 2002, s/n). La adquisición de tractores por algunos ejidatarios, no trajo consigo la apropiación de parcelas, debido a que era más redituable prestar los servicios de barbecho, rastreo, desvare y siembra que invertir en cultivos, con lo que se activó el espíritu empresarial de algunos ejidatarios.

Este patrón de acumulación de capital en la agricultura incluyó la incorporación creciente de maquinaria e implementos. Hacia 1970 dejó de ser negocio la inversión en tractores dado que muchos ejidatarios poseían al menos uno y fueron las máquinas trilladoras combinadas las que constituyeron el medio principal de acumulación de capital, dada la introducción masiva del cultivo de sorgo y cártamo en la ciénaga de Chapala.

Desde los años 60 con el inicio de la Revolución Verde, se planteó como necesidad nacional incrementar la producción en el campo a base de la selección de las semillas, el enriquecimiento de los suelos, la construcción de infraestructura hidráulica y la mecanización a partir de implementos agrícolas, pero fue hasta los años setenta que se alcanzaron altos grados de tecnificación en la producción agrícola. La introducción de agroquímicos y nuevas tecnologías requería de una inversión de capital que muy pocos ejidatarios poseían, y que eran aquellos que se convirtieron en prestamistas y adquirieron los primeros tractores.

Sin embargo, el verdadero negocio era la producción y venta de maquinaria e implementos agrícolas y la agricultura no eran más que un medio de conversión de la plusvalía en capital. 
Artículo científico - Humanidades

Los ejidatarios fueron vendiendo sus tierras y junto con sus descendientes se incorporaron a las filas del proletariado, muchas de las veces laborando en parcelas que antes fueron de su propiedad.

La agricultura fue exigiendo cada vez una mayor masa de capital invertido en medios de producción, generando en lo inmediato desempleo y migración a las grandes ciudades y a los Estados Unidos de América. Pero, a partir del año 2000 la instalación de empresas agroindustriales en la región, generó una fuerte demanda de fuerza de trabajo e inició el uso de plásticos en la agricultura.

\section{El uso de plásticos en la agricultura}

En las costas orientales del lago de Chapala, desde antaño y de forma estructural se implementó un sistema de producción de granos tal como el Bajío, el "granero de México" con una alta producción. La desviación del cauce del río Duero a finales del siglo XIX tuvo como finalidad regar cultivos de trigo en la zona oriental del lago de Chapala, y la reducción del nivel de retén del entronque del lago con el río Santiago, la de ampliar la superficie cultivable de trigo. Posteriormente, la dependencia del mercado mundial obligó a introducir nuevos cultivos financiados por grandes empresas agrícolas (Ávila et al., 2017, 20) y a cambiar el uso del suelo.

De acuerdo con la información proporcionada por Comisión Nacional del Agua (CONAGUA, 2019) en su Distrito de Riego 024, existe una tendencia a la ampliación de la superficie dedicada al cultivo de fresa. En el año 2015 se sembró maíz en 4,213 ha, mientras que de fresa se sembraron 280 ha; para el 2016 el maíz ocupó 7,200 ha y la fresa 631 y, en 2017, el maíz alcanzó las 4,803 ha y la fresa cubrió 423 ha.

La superficie sembrada puede indicar que no hay cambios y que el maíz sigue siendo la producción fuerte en la ciénaga de Chapala. Sin embargo, a pesar de la diferencia de las hectáreas sembradas de estas dos especies, la fresa superó con alrededor de 100 millones de 
pesos en ganancias al maíz. En 2017 aparece un fenómeno biológico relevante: la entrada masiva del pulgón amarillo que ha mermado el interés por la producción de granos en la región y en general en todo el país (Villagómez, 2019), lo que favorece el cultivo de otras especies.

El paisaje agrario se va transformando con los nuevos cultivos, porque requieren nuevos materiales y tecnologías, como sucede con el uso de plásticos, la extracción de agua profunda, el riego por goteo y la utilización de agroquímicos (Figura Núm. 1).

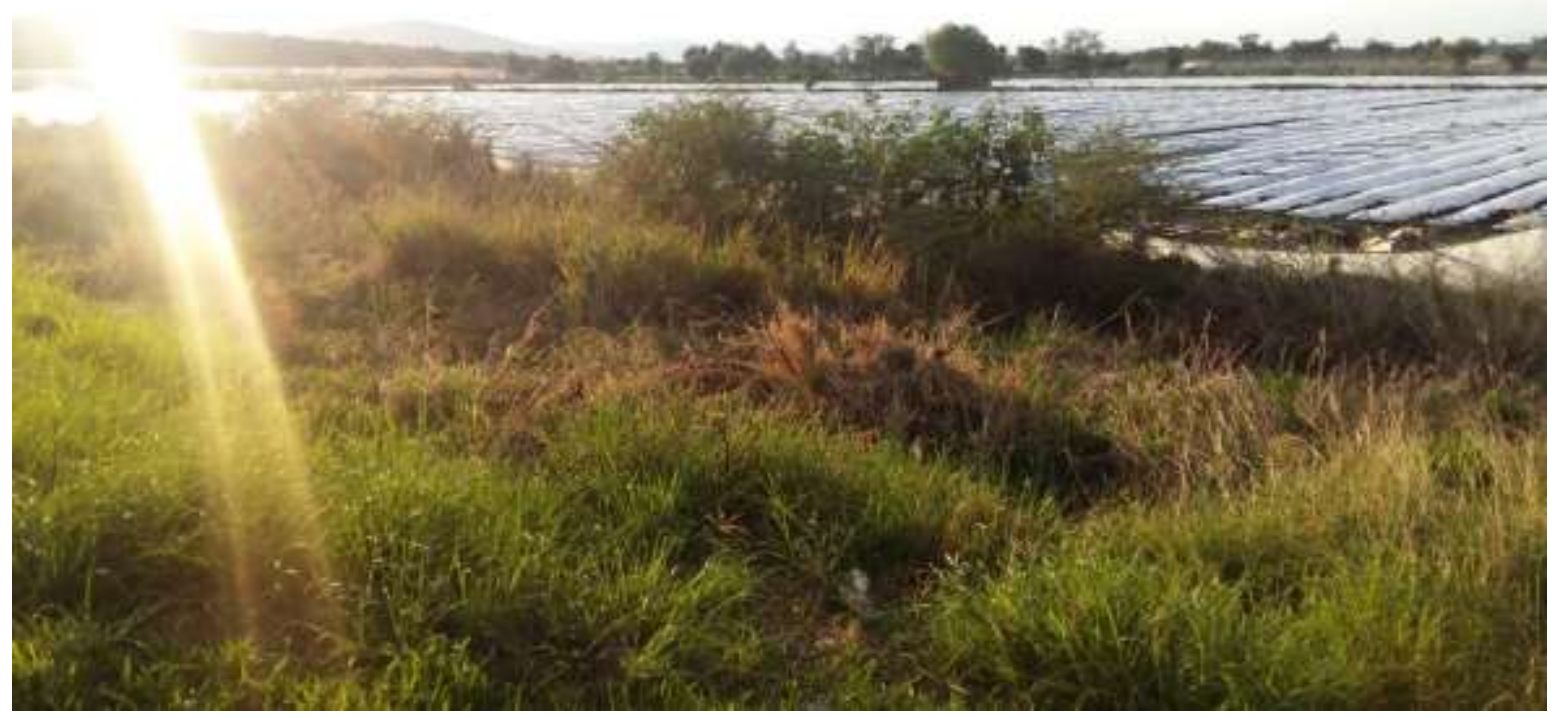

Figura 1. Plasticultura incursionando en forma de acolchados en cultivos de la ciénaga de Chapala, México. Fuente: Acervo fotográfico de la investigación. Tomada el 25 de julio del 2019.

Los plásticos han incrementado su presencia en las parcelas, transformando el paisaje de la ciénaga de Chapala. Midiendo la superficie ocupada por acolchados, túneles e invernaderos en las imágenes satelitales de la ciénaga, se observó un incremento de acolchados de 1,228 ha del año 2006 al 2019; de 433 ha de túneles y 26 ha de invernaderos para el mismo período. La Tabla 1 muestra el incremento en los últimos años del uso de plásticos en la agricultura en la zona de estudio. 
Tabla 1.

Plasticultura en la ciénaga de Chapala

\begin{tabular}{ccccccccc} 
Año & 2006 & 2011 & 2014 & 2015 & 2016 & 2017 & 2018 & 2019 \\
\hline Acolchados (ha) & 222 & 832 & 785 & 825 & 1314 & 1073 & 1391 & 1450 \\
Túneles (ha) & 26 & 42 & 111 & 88 & 471 & 535 & 531 & 459 \\
Invernaderos (ha) & 0 & 8 & 26 & 34 & 13 & 11 & 8 & 26
\end{tabular}

Fuente: Elaboración propia con datos de superficie calculados con Google Earth.

Los invernaderos y túneles plásticos permiten un mejor control del clima y la implementación de nuevas tecnologías y por ello se usan los túneles en grandes extensiones; el acolchado mantiene una alta temperatura en el surco, conserva la humedad e impide la formación de malezas y el desarrollo de plagas en el suelo. Además del alto volumen de los plásticos utilizados en acolchado, túneles e invernaderos, en el proceso de producción y comercialización se utilizan materiales plásticos con una vida útil corta y de lenta degradación, que generan zonas de acumulación de basura que degradan el paisaje.

El uso de plásticos en la agricultura va más allá de la producción de frutillas y hortalizas, pues se está convirtiendo en una técnica utilizada incluso en el cultivo de maíz, con la nueva tecnología de camas que substituye al surco.

\section{Las tendencias}

La contratación de mano de obra de manera masiva por la agroindustria, estimula movimientos migratorios y cambios en los comportamientos sociales (Costantino, 2016, 138), en los servicios y en la infraestructura necesaria para satisfacerlos como caminos, medios de transporte, fuentes de energía y agua, entre otros.

Los jornaleros agrícolas influyen en la transformación del paisaje agrario generando desechos de origen plástico, como envolturas de comida chatarra, vasos, platos, tenedores, popotes, etc., que se incorporan a los desechos de procedencia agrícola de las grandes empresas, como sucede con las mangueras de riego, los plásticos de acolchados, invernaderos y túneles 
abandonados o caducos, así como los productos de embalaje de la fruta de exportación dañados. Estos desechos plásticos son apilados en determinados sitios de la región y posteriormente incinerados. Los pequeños agricultores también aportan envases de pesticidas, fertilizantes, refrescos y platos y vasos desechables que terminan a las orillas de los canales de riego y las brechas (Figura Núm. 2).

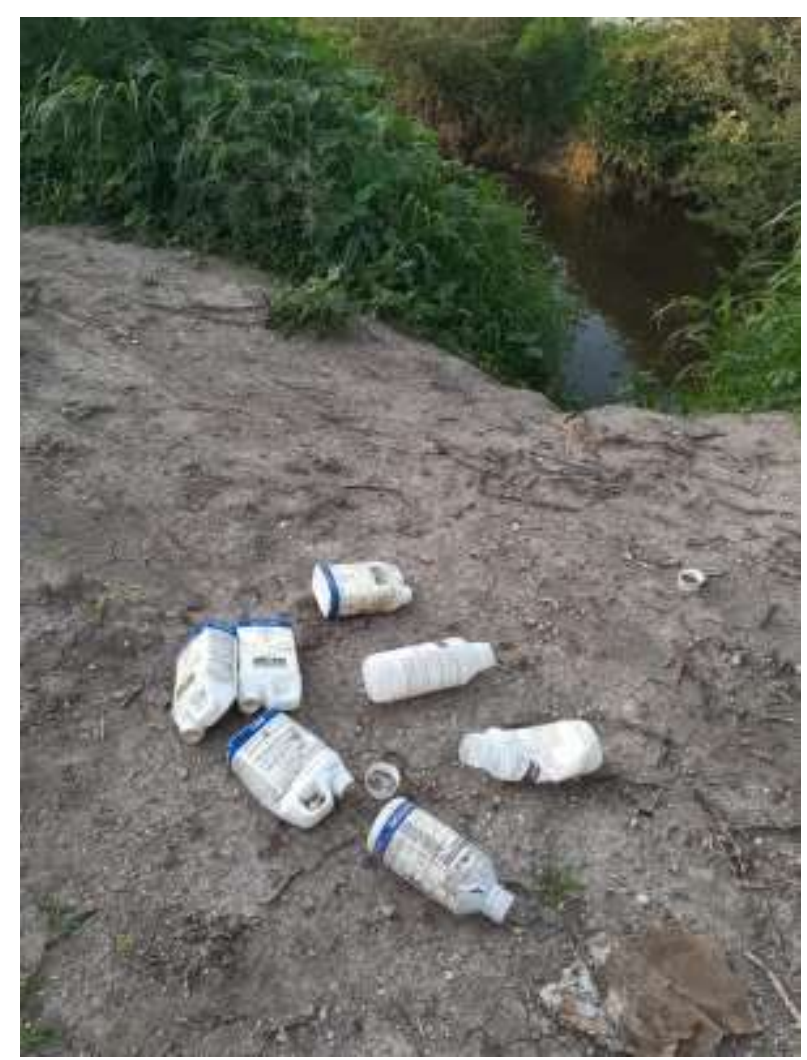

Figura 2. Envases plásticos de agroquímicos a orillas de canales de riego en la ciénaga de Chapala, México.Fuente: Acervo fotográfico de la investigación. Tomada el 01 de agosto del 2019.

Actualmente contrastan los nuevos tendidos eléctricos que hoy día se distinguen en la falda del cerro de San Francisco, entre Jiquilpan y Villamar, en los márgenes de la ciénaga de Chapala, con la incipiente compañía generadora de energía que a principios de siglo fundó el gobernante Cuesta Gallardo (Tortolero, 2002, s/n) en la misma región.

Los cambios que ha sufrido el paisaje agrario y su conformación entre parcelas de distinto tamaño y denominación en la ciénaga de Chapala. Esto, se observa también contrastando los 
cultivos de maíz, trigo, sorgo e incluso cártamo, con la llegada de la sandía, cebolla, jitomate, fresa, frambuesa y zarzamora, motivada por la demanda de esos productos en el extranjero y que, como dice la "gente del campo" de la región: "eso no da de comer" pues se trata de productos de exportación, que no ayudan al consumo local de productos básicos en su dieta y sí transforman notablemente el paisaje.

El cambio de cultivos en la región aunado al continuo incremento en el uso de plásticos, incrementa el volumen de la basura plástica (Figura Núm. 3), si bien la proporción de terrenos que están plastificados actualmente es menor al 10\%. Pero la tendencia es a su aumento y no ha sonado la alarma que avise del peligro que se acerca, a pesar de la fuerte transformación del paisaje que está generando.

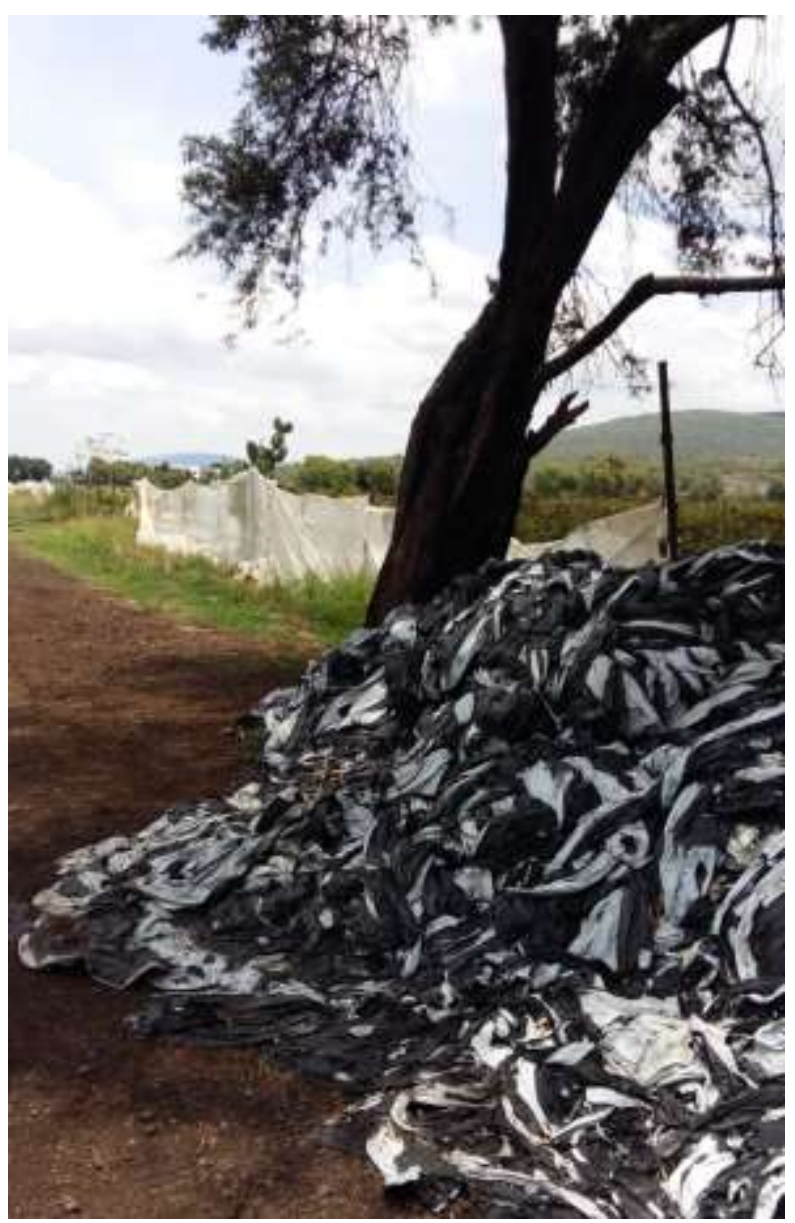

Figura 3. Desperdicio y acumulación de plástico agrícola en la ciénaga de Chapala, México. Fuente: Acervo fotográfico de la investigación. Tomada el 25 de julio del 2019. 


\section{Conclusiones}

Los ejidatarios de la ciénaga de Chapala transitaron de campesinos que producen para el autoconsumo a productores de mercancías. En esa transición, muchos abandonaron o vendieron sus parcelas y se convirtieron en vendedores de su fuerza de trabajo. Los ejidatarios que aún poseen parcelas las rentan, en tanto que la gran mayoría se han proletarizado y muchos de ellos se han convertido en jornaleros que trabajan para corporaciones agroindustriales.

Fueron las empresas agroindustriales las que introdujeron el uso de plásticos en la región. Hoy día su utilización se ha ido extendiendo a cultivos que en el pasado resultaban inimaginables. Es el caso del uso de acolchados en camas para cultivo de maíz en tres surcos y el acolchado de surco doble en el cultivo de garbanza. Así entonces, el uso extensivo de plásticos en la agricultura está transformando gradualmente el paisaje agrario de la ciénaga de Chapala a pasos constantes. La agricultura es una actividad que paulatinamente está siendo apropiada por la agroindustria, cuyas tecnologías están transformando el paisaje, las relaciones sociales de producción y la cultura de los pueblos. Usa el territorio y la población para generar productos que serán enviados a Norteamérica, Europa y Asia.

Los estragos causados por el uso de plásticos en la agricultura se empiezan a observar en las tierras de la región, por los cambios que generan en el paisaje y por la basura que generan. Existen grandes cantidades de residuos plásticos en sus diversas formas, a orillas de canales de riego, brechas entre parcelas y caminos vecinales. Y la alarma no ha sonado aún.

\section{Referencias}

Ávila Romero, A., M. Carámbula Pareja, A. Rodrigues de Oliveira, L. E. Ávila Romero y M. Á. Pinkus Rendón. (2017). Reestructuración capitalista, dominio agroenergético y disputas territoriales en México, Uruguay y Brasil. Argumentos, 30(83), 17-42.

Boehm Schoendube, B. (2005). Agua, tecnología y sociedad en la cuenca Lerma-Chapala: Una historia regional global. Nueva antropología. 19(64) 99-130.

Burton, T. (1997). ¿Se podrá salvar el mayor lago de México? Un esfuerzo internacional de rehabilitación viene en camino. Ecodecisión, 23, s/n. 
Castillo, Neztor. (2010). Los beneficios del plástico en la agricultura. Industria y negocios. pp. s/n. Recuperado de https://revistaindustria.com/2010/07/jul-10-los-beneficios-del-plastico-en-laagricultura el 20 de abril del 2020.

Comisión Nacional del Agua (CONAGUA), (2019). Archivos de Estadísticas Agrícolas Anuales 2000-2017. Jefatura de Operación, Distrito de Riego 024 Ciénaga de Chapala. México.

Costantino, A. (2016). El capital extranjero y el acaparamiento de tierras: conflictos sociales y acumulación por desposesión en Argentina. Revista de Estudios Sociales (55), 137-149.

Tortolero, A. (2002). Modelos europeos de aprovechamiento del paisaje agrario: la desecación de los lagos en México entre el porfiriato y la revolución. XIII Economic History Congress. (pág. s/n). Buenos Aires: History Association. Recuperado de http://eh.net/XIII Congress/cd/papers/17Tortolero305.pdf el 19 de noviembre de 2006.

Trujillo Bautista, J. M. (2015). El ejido, símbolo de la Revolución Mexicana. Estudios Agrarios (58), 125-151.

Villagómez López, E. (julio de 2019). Comunicación personal. Jiquilpan, Michoacán. México. 